Please quote as: Menschner, P. \& Leimeister, J. M. (2012): Devising a Method for Developing Knowledge-Intense, Person-Oriented Services - Results from Early Evaluation. In: 45. Hawaii International Conference on System Sciences (HICSS), Maui, USA. 


\section{Devising a Method for Developing Knowledge-Intense, Person-Oriented Services - Results from Early Evaluation}

\author{
Philipp Menschner \\ Kassel University - Information Systems \\ menschner@uni-kassel.de
}

\author{
Jan Marco Leimeister \\ Kassel University - Information Systems \\ leimeister@uni-kassel.de
}

\begin{abstract}
In this paper, we present a method for engineering person-oriented services (EPOS) and discuss its suitability to the systematic development of ITsupported knowledge-intense person-oriented services (KIPOS). We provide (1) a criteria-based evaluation and (2) insights from an ongoing action research project. KIPOS, predominately existent in sectors as health care or education, are of high economic relevance regarding market size and growth, yet are laggards in realization of IT-potentials. Leveraging ITpotentials as automation, standardization, or intelligent customer integration could be used to increase quality and reduce cost. This is hard to achieve, as value-creating activities within KIPOS are bound to persons or personal knowledge, making their design complicated. We apply a criteria-based evaluation for the method developed. The results show that EPOS meets the requirements for engineering KIPOS. Additionally, we provide insights from an action research project providing evidence that the method is also applicable for engineering KIPOS in real-world settings.
\end{abstract}

\section{Introduction}

Essential to the successful development of services is that they are underlined by a reasonable service process and design. In the 1990s, service engineering (SE) emerged particularly in Germany. It can be traced back to concepts of new service development and service design which evolved in the 1980s, mainly in the field of services marketing $[55,19]$. SE focuses on adopting concepts which are successfully implemented in product and software engineering to services. It is defined as the systematic design and development of services by deploying engineering methods, practices, and tools [13]. SE is of high relevance for IS research, as IT changes services in two ways: first, the use of IT contributes by enabling faster and more structured development processes; second, new services arise by applying IT. Thus, most service innovation today is about the adoption and effective implementation of IT
[63]. The innovative application of IT, however, varies among service industries [58]. Especially knowledgeintense person-oriented services (KIPOS), predominately existent in health care or education, are still lagging behind on reasonable use of IT. Examples are nutritional or health counseling, which are highly individualized, knowledge-demanding, and generally delivered face-to-face. Additionally, they are characterized by a high degree of customer interaction and are bound to persons or personal knowledge [39]. Despite little statistical data being available for KIPOS, they bear great economic potential. Health care, as just one example, comprises highly complex and extremely expensive services that have a significant impact on economies and the quality of patients' daily life [45]. Germany, for example, spent more than 250 billion Euro on healthcare in 2009 , and costs are projected to increase by $70 \%$ by 2020 , with large portions going into KIPOS [30]. If the same increase in productivity, quality, and growth shall be achieved with such services as has been experienced during the industrial revolution around manufacturing products, reasonable IT support, structured development methods, and routines become crucial enablers for industrializing services [6].

Realizing IT-potentials for such services raises problems, as their design incorporates both the design of people-bound activities and technological infusions, as well as their interrelation [40]. Yet, several new technologies have been developed and introduced which might lead to IT-enabled service innovations also in these sectors $[41,7]$. Despite this, only a few of these innovations have been put into practice [20].

The objective of this paper is thus to introduce the Engineering of Person-Oriented Services (EPOS) method and show its suitability for the systematic development of KIPOS. First, we present requirements for engineering KIPOS, and discuss related work. We then briefly explain the EPOS method and discuss the extent to which it meets the requirements, representing a criteria-based evaluation. This is followed by insights of applying the method in an action research project to the case of nutritional advisory for obesity. 


\section{Requirements for engineering KIPOS}

Knowledge-intense services are defined as follows: during production or process, the generation or the use of novel knowledge accounts for a large proportion of the service [26]. These services are predominantly found in industries such as consulting, health care, or education. Others use the expression "informationintense" with a similar definition: information action amounts for the largest proportion of value created by the service system [4]. KIPOS are additionally characterized by a high degree of customer interaction and are bound to persons or personal knowledge [39]. To define KIPOS, the concept of service system can be adopted. Following this approach, KIPOS can be defined as follows: A KIPO service is a knowledgeintense service system which incorporates one or more person-to-person-encounters as a fundamental and integral part of the service. Certain distinct characteristics of KIPOS mandate a customized SE approach. These are: individual history of customers, emotional ties, high degree of implicit knowledge, and people-boundness [39]. Based on the key characteristics of KIPOS and their impact on SE [40, 39], a set of requirements can be developed and translated into applicable goals.

As SE involves the systematic development of services using models, methods and tools, it is important to define these terms. According to Brinkkemper [11], a method is an approach that describes the conduction of an entire development process or project. It provides detailed prescriptions of how to perform a collection of activities. A technique can be defined as a part of a method that gives concrete and tangible instructions on conducting an activity. A technique is defined as "a procedure, possibly with a prescribed notation, to perform a development activity." Thus, a method provides a systematic approach of how to use different techniques. A tool is an automatic way to support a part of the development process. Hence, in order to be a SE method, an approach needs to cover the entire development process, and the steps have to be described in detail. Based on this, the first two design goals are:

g1: Life-cycle coverage: All phases of the engineering process must be included in the method, ranging from analysis of the underlying problem domain until implementation of the KIPO service.

g2: Granularity of approach: Precise actions on how to act have to be stated.

As the focus of this paper is IT-enabled KIPOS, requirements are also derived from the integration of certain design elements, the application of IT, and integration of customers into service provision, partially enabled through IT. Yet, a closer analysis shows that KIPOS settings contain processes that should be continued to be delivered personally, as they are the most value creating activities [20]. Furthermore, IT can make a contribution by supporting these processes with IT systems, e.g., by providing information or templates that make the provision more efficient. Additionally, there are typical service candidates for automation, e.g., services that contain sub-processes or activities that are partly standardized for several clients, or those that add value. These could be automated and delivered by IT systems to enable scalability. The following aspects are in need of consideration. Thus, the method needs to:

g3: support modeling of the information and knowledge intensity,

g4: support the development and design of personoriented service processes,

g5: allow the integration of IT, resp. modeling of IT and software components,

g6: provide decision support on automation and customer integration, i.e., the method needs to allow identification of must-have person-to-person encounters and potentials for automation by IT, and

g7: support the interaction of technical components and people-bound process steps.

Additionally, integration of new technology leads to completely new and unknown services. As the development of such innovations is computing within a user's changing environment, it is important to determine user needs at a very early stage of development [28]. User needs are to be reflected in more specific requirements which in case of fulfillment satisfy the user's needs. Recent studies underline the potential of involving users, as this can result in more innovative services that have greater user value [35]. Additionally, as user requirements are often "sticky" information, significant costs are involved in eliciting these requirements in non-participatory design settings [46]. Hence, participatory design and prototyping approaches are also paramount for high acceptance of IT-enabled KIPOs. This leads to the last aspect:

g8: Participatory development: Customer integration needs to be provided for the entire engineering process.

The following section presents the examined body of literature as well as the results these sources revealed in terms of the analyzed aspects.

\section{Related work}

As [40] point out, there is a lack of methods that meet the requirement of a comprehensive SE approach for developing IT-enabled KIPOS. The analyzed articles can be allocated to different groups. The first group comprises approaches that can generally be 
classified as frameworks and process models. Identified shortcomings of these approaches are: an insufficient level of detail (i.e., no concrete actions or methods to be deployed are described), a lack of practical corroboration, as well as insufficient IT support [48]. The second group encompasses approaches that focus mainly on sub-categories of SE, e.g., user experience or service quality. Only a few articles present comprehensive approaches. Some works compare different approaches on a specific service and contribute to SE theory, yet they do not present novel methods or guidance. Additionally, a range of works can be identified that analyze the impact and challenges that arise through technology infusion into the service encounter. However, these approaches, e.g., [61], focus mainly on multi-channel service delivery, concentrating mainly on the service encounter and neglecting back-office processes. Details can be found in [40].

Table 1 summarizes the analysis of related works. For $g l$ and $g 2$, trivalent scales $(0,+,++)$ are used with the following semantics: 0 stands for no life-cycle perspective at all, while + indicates approaches which integrate a life-cycle perspective, but do not cover it in a comprehensive manner. Finally, ++ represents approaches covering the whole life-cycle. Therefore, we use Bullinger and Schreiner [14] as our reference life-cycle model that dictates the completeness criterion, as their model is a reference model based on other approaches. Considering the granularity of the approach, 0 is used for approaches that only present very light-weight approaches, and are limited to the presentation of meta-levels and major process steps: + represents approaches that clearly describe their main process steps, but in contrast to ++ , do not elaborate on actionable advice regarding the corresponding process steps. For all other analyzed aspects, the heterogeneity and unpredictability of potential assessments suggest a mere textual evaluation which allows an adequately flexible reflection.

Previous research has clearly indicated that development methods must be adapted and tailored to the specific context in which they are used [27]. To overcome the deficits of existing approaches, the concepts of method engineering (ME) [11] could be used to outline what a consolidated method might look like. Concepts of ME, amongst others, are method integration or "best of breed" approaches to combine different fragments of existing methods. Some recent studies already follow an ME approach, e.g., by combining service blueprint with FMEA [16], or by integrating QFD with Gap-Analysis [29]. Other works successfully extend existing approaches by integrating other views and techniques, e.g., by extending service blueprints [48] or the TRIZ method [15]. These articles present good starting points for further consideration of method integrations, which we build upon.

One of the main challenges in engineering KIPOS is in the duality of people-bound activities and IT components. First starting points on how this conflict could be addressed can be derived from works trying to design multi-channel service encounters [61, 48]. These works could potentially be extended to analyze the whole service process, i.e., in their current states they address only the service encounter. Other interesting starting points for dissolving this duality are the approaches of [15], who apply the TRIZ method to overcome conflicting design issues. Yet, they do not explicitly address technology infusion. For integrating an information and knowledge dimension, the approaches of Froehle and Roth [23], and Qi and Chuan Tan [51] present starting points.

Table 1. Comparison of Existing Service Engineering Approaches (according to [40])

\begin{tabular}{|c|c|c|c|c|c|c|c|c|c|}
\hline & g1 & g2 & g3 & g4 & g5 & g6 & g7 & g8 & Comments \\
\hline [1] & ++ & 0 & no & no & no & no & no & $\begin{array}{c}\text { yes, customer } \\
\text { feedback for all } \\
\text { stages identified }\end{array}$ & proposes 2 new NSD processes \\
\hline [8] & + & ++ & no & yes & no & no & no & $\begin{array}{l}\text { partially, focus on } \\
\text { employees }\end{array}$ & extends service blueprint \\
\hline [9] & ++ & + & no & yes & no & no & no & yes & \\
\hline [14] & ++ & 0 & no & no & no & no & no & partially & uses a reference model \\
\hline$[15]$ & 0 & ++ & no & $\begin{array}{l}\text { no, focuses on } \\
\text { problem } \\
\text { elimination } \\
\end{array}$ & no & no & $\begin{array}{l}\text { partially, as this can } \\
\text { be modeled via the } \\
\text { function diagram }\end{array}$ & no & $\begin{array}{l}\text { uses principles for problem } \\
\text { solving }\end{array}$ \\
\hline$[16]$ & + & ++ & no & yes & no & no & no & yes & $\begin{array}{c}\text { is based on service blueprint and } \\
\text { FMEA }\end{array}$ \\
\hline [19] & ++ & + & no & yes & no & no & no & yes, customer focus & \\
\hline [21] & 0 & ++ & no & yes & no & no & no & no & extends service blueprint \\
\hline [23] & yes & 0 & $\begin{array}{c}\text { partially - intellectual } \\
\text { resources are } \\
\text { included }\end{array}$ & no & no & no & no & $\begin{array}{c}\text { not explicitly, } \\
\text { covered by several } \\
\text { identified constructs }\end{array}$ & $\begin{array}{c}\text { combines resource and process } \\
\text { based approaches }\end{array}$ \\
\hline [25] & 0 & + & \begin{tabular}{|l|} 
no \\
\end{tabular} & yes & no & no & no & no & focuses on service concept \\
\hline [32] & + & 0 & no & no & no & no & no & $\begin{array}{l}\text { only stating that } \\
\text { customer input is }\end{array}$ & $\begin{array}{l}\text { focuses on managerial } \\
\text { implications }\end{array}$ \\
\hline
\end{tabular}




\begin{tabular}{|c|c|c|c|c|c|c|c|c|c|}
\hline & & & & & & & & essential & \\
\hline [33] & ++ & + & no & yes & no & no & no & yes & focuses on developer teams \\
\hline [37] & 0 & + & no & no & no & no & no & $\begin{array}{l}\text { yes, focus of the } \\
\text { study is to highlight } \\
\text { the importance of } \\
\text { customer integration }\end{array}$ & focuses on idea generation \\
\hline [38] & ++ & + & no & yes & no & no & no & only in testing & focuses on testing services \\
\hline [42] & ++ & 0 & no & no & partially & no & yes & yes & $\begin{array}{c}\text { integrates software and service } \\
\text { engineering }\end{array}$ \\
\hline [48] & + & ++ & no & yes & yes & no & Yes & partially & $\begin{array}{c}\text { focuses on multi-channel } \\
\text { encounters, based on service } \\
\text { blueprint } \\
\end{array}$ \\
\hline [51] & ++ & 0 & partially & no & partially & no & no & no & $\begin{array}{c}\text { incorporates a knowledge } \\
\text { dimension }\end{array}$ \\
\hline [52] & ++ & + & no & yes & no & no & no & yes & includes service management \\
\hline [55] & ++ & + & no & no & no & $\begin{array}{l}\text { possibly in } \\
\text { specific test } \\
\text { phases }\end{array}$ & & no & comprises very detailed phases \\
\hline [62] & ++ & ++ & no & yes & no & no & no & employees only & $\begin{array}{l}\text { is based on QFD, Service } \\
\text { Blueprint and Stage Gate Model, } \\
\text { rather testing methods than } \\
\text { providing new methods }\end{array}$ \\
\hline [64] & ++ & + & no & yes & no & no & partially & yes & incorporates learning process \\
\hline [67] & ++ & + & no & no & no & no & partially & yes & based on TRIZ \\
\hline [66] & ++ & + & partially & partially & yes & no & partially & yes & $\begin{array}{l}\text { represents framework only, no } \\
\text { actionably advice; depending on } \\
\text { methods chosen within } \\
\text { framework }\end{array}$ \\
\hline
\end{tabular}

\section{The EPOS method}

Before presenting our Engineering of PersonOriented Services (EPOS) method, we provide clarification and a definition of our understanding of method. The term method is closely related to ME [11]. Here, method refers to a particular procedure for attaining something [44]. ME conceives methods as a set of disparate fragments. These method fragments need to be stored in a repository, that are standardized and then used to compose a new method based on the project situation. However, ME assumes preestablished, formal methodologies that are used to derive method fragments. In the case of personoriented services, this proves to be difficult, and, as such, a formal approach is impractical when addressing social and personal aspects in SE. Hence, we adapt the ideas of Karunakaran et al. [31], that is, using knowledge units instead of fragments, and deriving those from best practices and templates. This leads to our notion of method. A method is a process that is planned and systematic in terms of its mean and purpose [10]. Characteristic features of methods are goal-orientation, a systematic approach (rules on how to act and precise tasks for achieving goals), principles (design-guidelines, strategies, templates, and reference models), and repeatability. In the next sections, we present and discuss the EPOS method in detail. We present the elements of the method, discuss their relation, and provide examples from our empirical work as well as from the literature.

EPOS has been developed to enable the integrated design of IT components and people-bound activities following an engineering approach. The method includes five key stages (details see Figure 1):

1. Understanding the problem domain

2. Defining design goals

3. Performing analyses to inform design

4. Designing service

5. Evaluating

Each of these key stages is described in the sections that follow. Iteration is not only permitted, but also recommended in order to manage risks and to deal with changing requirements and unknown user experiences.

Step 1: According to Dubberly et al. [18], any design or engineering process starts with observations and investigation of the initial situation. Step 1 hence starts with an in-depth analysis of the socioorganizational problem. The main challenge when trying to realize IT-potentials within KIPOS is that integration of new technology leads to completely new and unknown services, and hence can be regarded as computing within a users' changing environment [28]. This poses difficulties on eliciting requirements, as users can hardly imagine the scope and utility of the potential solution. Additional challenges derive from specific characteristics of person-oriented services, such as emotional ties and stress. To overcome these difficulties, EPOS uses qualitative methods to get a detailed understanding of the problem situation. This 
involves data collection techniques such as focus groups, case studies, interviews, questionnaires, observations, and document analyses [68]. This procedure is inspired by ethnomethodology-informed design $[17,36]$. The goals of step 1 encompass several stages: identification of information deficits, customer needs, provider needs, communication needs, shortcomings of existing service offerings, and processes. The tools that can be used within this stage are mainly qualitative methods. The outputs of step 1 are the process of the existing service in the form of a service blueprint, and a list of user and customer needs.

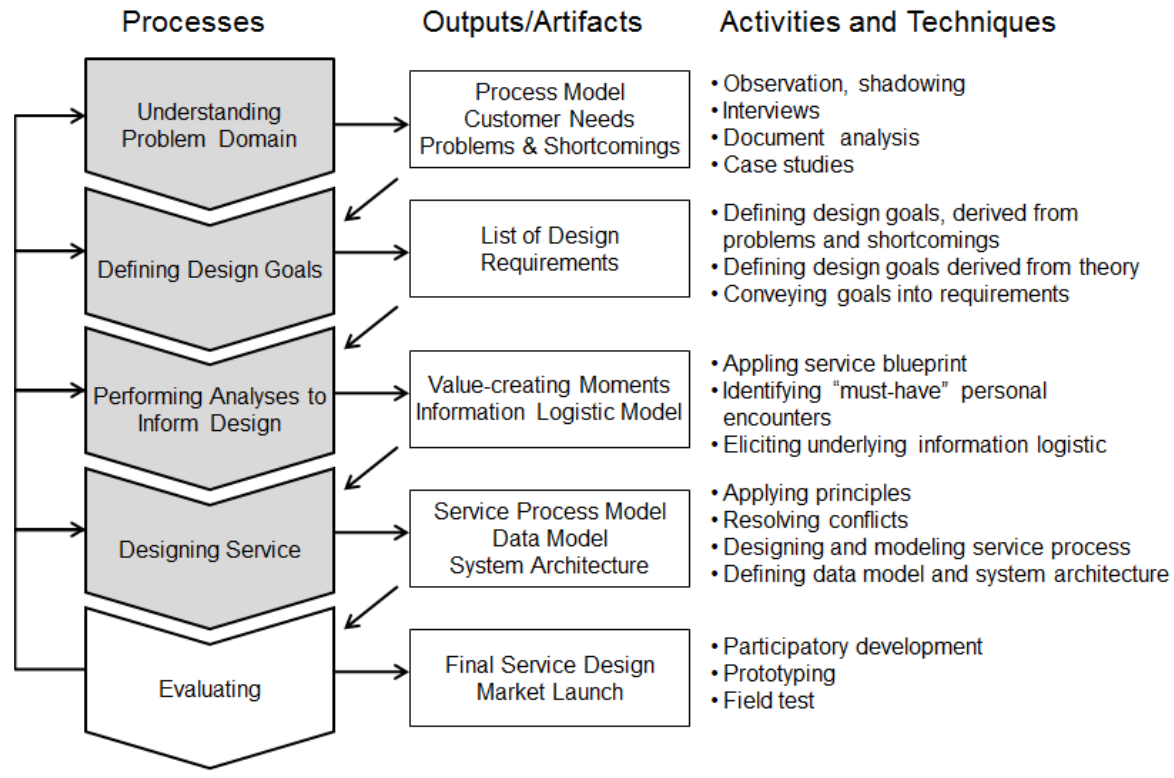

Figure 1. The EPOS method

Step 2: Essential to the design of the new service is that it is underlined by design strategies. These can be either informed by the problems and shortcomings identified within step 1 , be derived from service provider or customer needs, or drawn from theories [50]. The goal of step2 is hence to provide transparency regarding the overall design goals for all stakeholders. This comprises a documentation of the main design goals, and communicating these amongst stakeholders to ensure that the goals can be discussed and interpreted from all points of view. Design goals are essential to further SE process, as they form the basis for evaluating the proposed service design. The output of step 2 is a list of design goals and general design requirements. Hereby, it is important to ensure that the requirements are technologically independent. Step 3: Step 3 is at the core of the EPOS method, guiding the engineer through the analysis and leading to first design implications. The main challenges in EPOS can be traced back to two concepts: (1) any increase in efficiency (application of standardization or automation) is closely related to the understanding and acquaintance of the customer. Hence, goal-oriented and satisfying service delivery is dependent on a solid information base of the customer [39]. (2) The second insight is service experience; accordingly, the value created for the customer is people-bound. KIPOS are performed for people, and the dominant factor for perceived service quality is the person providing the service. Thus, it can be concluded that services contain at least some partial processes that must remain as they are: person-to-person encounters. Therefore, such "must-have" personal encounters need to be identified. The goal of step 3 is hence two-fold: Identifying valuecreating moments and gain an understanding of the underlying information logistics. For identifying valuecreating moments, service blueprinting proves to be valuable. Service blueprinting is a process analysis method originally proposed by Shostack [59]. Creating a service blueprint requires the mapping of all key activities involved in service provision as well as the linkages between these activities. Zeithaml et al. [69] define service blueprinting as a tool for simultaneously depicting the service process and the points of customer contact. Here, the line of interaction requires further attention. It separates customers from provider activities and represents joint activities.

Within KIPOS, multiple activities reside on this line, with the majority of value creating activities taking place during, e.g., consultation hours. By applying the lean principles [65] on these activities, the value-creating moments can be identified. To grasp the underlying information logistics, first a model of information flows needs to be elicited. The challenge 
in modeling the data need for service provisions lies in determining an adequate data basis. It should not be the intention to elicit as much data as possible, but to decide which granularity of data is necessary to fulfill the design goals of step 2. The outputs of step 3 are: (1) Activities in the service process that need to remain person-to-person encounters. All remaining process steps are candidates for automation and customer integration, or can be removed. These decisions are performed in step 4. (2) A model of the data logistics is needed in order to provide support for decision making, especially for the granularity of data points.

Step 4: Based on the outputs of step 3, this phase comprises the development of the service design. EPOS provides principles and templates that inform the service design. Principles are sets of rules that guide the engineer and are derived from analyzing prior SE projects, best practices, and theories [50]. The first goal within step 4 is to reduce face-to-face contacts within the candidates identified in step 3 to essential activities. For example, if a process step resides completely on the line of interaction, this can be resolved by applying the principle segmentation. This separates this activity into more detailed parts and allows reassessment of each part on whether it is a necessary face-to-face contact. Then, the feasibility of automated customer integration can be checked, and the conceptual archetypes of customer contact $[22,24]$ can be applied to these parts.

EPOS provides a set of design principles that can be applied to each process step. Based on these principles, any process step can be analyzed, deconstructing the problem into concise design tasks. Non-value-creating activities can be automated, semiautomated (offering the provider the chance to intervene), or be moved to the customer. The output of step 4 is hence a service blueprint representing the new service design, a structured model of necessary data to support (semi)automated process steps, and the architecture of the underlying IT system. These three can then be put together for building a first prototype. Yet, principles sometimes have spillover effects that can negatively influence customer satisfaction and service quality. Identification and resolution of such conflicts can be resolved on a conceptual basis or addressed in step 5 .

Step 5: Participatory design and prototyping approaches have proven to be valuable to the development of mobile or ubiquitous computing services [28]. This also holds true for the design of KIPOS. Through early involvement of stakeholders in the development process and visualization of parts of the system through prototyping, the danger of transporting wrong or inaccurate requirements to the final system can be reduced [2, 12]. Additionally, general requirements become more detailed and refined with progression of the development process. Participatory design is hence paramount to achieving a high acceptance of IT-supported services. Within step 5 , the goal is to test and evaluate the service design developed in step 4 with potential users. Tools that can be applied here are prototyping, focus groups, and workshops with users and providers, following the approach of Resatsch et al. [53]. According to Nielsen [43], reliable results can be obtained with four to six persons for each iteration, and, a "good" design is reached once there are only minor or even no further changes in requirements during an iteration.

\section{Criteria-based evaluation of EPOS}

This section provides a criteria-based evaluation of the EPOS method and discusses how the method matches the requirements formulated in section 2 . Life cycle-coverage of design goal 1 (g1) is provided by EPOS, as it covers all phases from an initial service idea up to market readiness. EPOS starts with the acquaintance of an a priori understanding of the organizational context within step 1 to allow engineers to better interpret tasks, knowledge, and shortcomings. The method further guides the process through analysis and design, and then ends with evaluation of the ITsupported service in real-world settings. A minor critique is that there currently is no guidance on market launch. EPOS further comprises techniques and method fragments to be carried out during the single steps of the approach (g2). Guidance on how the different actions inform each other is provided, and artifacts representing products of single tasks are formulated. The method also provides guidelines that facilitate and inform not only the analysis, but also the creative process of service design and development.

By modeling the underlying information logistics in step 3 and developing a data model required for the system design, EPOS takes into account the knowledge-intensiveness of KIPOS (g3). The improvement of information logistics is addressed by applying the principle of electronic data capture.

Person-oriented process steps (g4) and the integration of IT (g5) are addressed by EPOS in multiple ways, comprising the main objective, as the method is envisioning IT-enabled KIPOS. For example, the identification of automation and customer integration potentials, i.e., the identification of musthave personal encounters (g6) is provided by applying the method of service blueprint within step 1 to identify customer interaction points and by further analysis and identification of value-creating moments and segmentation within steps 3 and 4. This allows for reducing person-to-person encounters to crucial and 
valuable activities, leaving residuary tasks as candidates for either customer integration or automation, both enabled by IT. To ensure that these components work together (g7), EPOS comprises a data model underlying the system architecture and the modeling of the service process taking into account customer interaction points, as well as roles and tasks of the underlying IT system in step 4. Further, side effects, usability, and practicability of the solution are tested within the evaluation phase in step 5.

Participatory development (g8) is provided from the beginning of the method. Interviews and focus groups within step 1 ensure that user needs and requirements are accounted for from an early stage. Within step 5, EPOS follows a prototyping approach that allows testing of the proposed service solution and ensures user acceptance. It can hence be concluded that EPOS fulfills the requirements described in section 2 .

\section{Applying the EPOS method}

This section presents results of an ongoing action research project serving as proof-of-concept evaluation for EPOS by providing additional insights, reflections, and learning on the method $[57,34,5]$. The objective was to determine how the method could best unfold its potential in practice, as well as to identify possible refinements and shortcomings. Against this research background, a nutrition advisory process for obese people was examined and engineered up to step 4 .

\section{Understanding the problem domain}

The data collection techniques used in this case involved qualitative interviews with nutritionists and obese women, as well as observations and shadowing. This step is essential to the method, as it allows not only identification of shortcomings within the existing service offering, but also strengths and essentials, thus leading to an understanding of the problem domain of obesity consultation. Identified shortcomings within the analysis were deficits and insufficiencies in information logistics. These were reflected by several soft copy documents of the nutritional adviser, such as impressions of the patient's personality, as well as by the patients' activities that were not documented at all. Furthermore, soft copy and hard copy documents of the nutritionist and the patient were fragmentary because they either consisted of different information or contained the same information in different ways. Additionally, patients were not obliged to continue their nutritional diary after their second meeting with the nutritionist, also resulting in incomplete data, as patients were not able to remember their intake precisely. Therefore, the nutritionist gained only a vague impression of the daily routines of patients. This dissatisfying information base was further hampered by media disruptions and proprietary data formats.

Apart from these weaknesses, it could be identified that the personal aspect within the patient-nutritionist relationship was very important in terms of customer trust, his/her compliance, and hence the success of the treatment. Thus, value-creating moments occurred mainly during consultation hours. Further, provider needs were long-term nutrition diaries supporting exact advice on the patients' training plans and nutritional intake. Customer needs were mainly guidance and advice during daily routine activities, such as food shopping or dining in a restaurant/canteen.

\section{Defining design goals}

Based on the findings in step 1, a major design goal is the improvement of data quality and consistency. This encompasses disposal of media disruptions and information asymmetry barriers between nutritionist and patient. As "high quality answers require rich information channels" [56], improving data relevant for treatment can lead to better prognoses for the patient's treatment, and therefore result in increasing trust of patients. With more consistent and complete data, time-savings can also be realized. Moreover, the design needs to aim at simplifying the processes between nutritionist and patient by breaking down the process into its components in order to reduce face-toface encounters - the most cost-intensive aspects along the value-chain. Another design goal is the design of lifestyle interventions dealing with motivational aspects ("make it fun, easy, and rewarding" [60]). High participation of patients can influence their intrinsic motivation positively. Further, high scalability is needed in order to reduce costs and to increase the applicability of the product for a wide variety of patients. Other objectives that can be realized by all design goals are: the patients' awareness of their situation through constant data collection, the option of controlling their progress in therapy, making the progress of treatment more tangible, as well as a higher willingness to transfer trustworthy data.

Performing analyses to inform design

The aim of step 3 is to solve the problem of maintaining value-creating, people-bound activities and, at the same time, realizing economies of scale through standardization and IT. It hence provides a systematic approach to identifying value-creating moments and identifying process steps for automation or removal. This is done by applying the principle of segmentation and lean principles to the service blueprint of the nutritional advisory. In this case, identified must-have personal encounters take place in the first consultancy, which serves in building up trust and a personal relationship, getting to know one another, and aiding the initial physical examination. 
The second appointment at the nutritionist also needs to remain personal, as this is the meeting after writing a nutritional diary. The second appointment is used to analyze the nutrition intake and develop a personal nutritional plan together.

All other activities can be broken down into smaller processes from which only one needs to remain personal. To reduce these face-to-face contacts, a set of design principles is applied to each process step. Since the principle of segmentation reveals process steps which are face-to-face encounters with high rate of "waste" time, relapsing activities, such as follow-up appointments, can thus be divided into several steps. In this way, the process steps consist of small anamnesis, analysis, discussion and decision on further treatment options, advice on correct behavior, and adjustment of the nutritional plan. Only the discussion and decision on further treatment options need to remain personal. All other process steps can be done either by the patient (e.g., collecting data for the anamneses) or by the nutritionist (e.g., the analysis of the patients' anamnesis and preparation of the suggested adjustment of the plan). Other principles, such as electronic data capture and standardization of process steps, lead to self-reported electronic data capture of nutritional intakes and physical activities by patients.

\section{Designing the service by applying principles}

Based on the previous analysis, this step comprises the modeling of the new service process, as well as the corresponding data model and system architecture. The aim in this case is the development of a real-time nutrition and activity documentation by electronic means such as PC, smartphones or tablets. This allows the removal of process steps such as sending physical documents between the nutritionist and patient. All documentation will be available online in real time, thus allowing independent analyses of the patients' status before appointments, as well as better preparation and time- and cost-savings on both sides. Moreover, the process of physical data input of nutrition diaries by the nutritionist is no longer needed due to electronic data capture, thus assuring increasing information quality. In the end, a new service blueprint emerges representing the new service design.

\section{Discussion of the EPOS method}

This case shows that the EPOS method can continuously be applied to derive a solution design for an IT-supported KIPOS. Overall, our experiences to date reveal that EPOS is reasonable, and depicts the potentials and possibilities that the method can offer to the design and development of KIPOS. Although we have demonstrated the application of the first four steps, a limitation is that the action research project is still ongoing. By the time of the conference, we hope to be able to present further insights from step 5 .

The novelty of our method is that it integrates techniques from IS development and service design, providing precise steps as well as principles that inform design. It thus offers a bridge between engineering approaches and social contexts. We focus especially on the early phases of SE. A common critique on most approaches is that the advancement from analysis results to the initial service design idea is not described properly or based on a systematic approach [48]. Design is a creative procedure, and yet it can be informed by principles and patterns that guide the engineer in deriving the solution [3, 54]. The novelty of our method is two-fold: We first close a gap evident in many SE methods, namely, by guiding the engineer in deriving the service design out of the analysis along precise tasks. Service design, in general, is a creative process; however, within the EPOS method it is guided and informed by principles and templates. Second, EPOS explicitly addresses the role of IT within services, and provides guidance on how to resolve the interplay between people-bound activities and semi-automation by IT.

The EPOS method hence contributes to SE by providing actionable advice on how to get design propositions directly out of service analysis by using service blueprints and principles. This differentiates EPOS from the approaches analyzed in section 3, who either present only high-level frameworks (e.g., [66, 23]) or focus on sub-problems only.

\section{Conclusion and future research}

In this paper, we have shown the applicability of the EPOS method to a special class of services, KIPOS. We presented requirements for engineering KIPOS and briefly described the method. We further provided a criteria-based evaluation of the method, and reported on an ongoing action research project of nutritional advisory for obese people. The contribution of this study is hence to show suitability of the method and provide proof-of-concept. The evaluation and the application of the EPOS method indicate that the method is appropriate. Our current experience with applying the method suggests that EPOS is valuable for engineering services. We hope EPOS stimulates further design research on IT-supported personoriented services, and fosters service innovations.

As we see options to refine and extend our work, our next steps are to continue our action research based evaluation by further developing the nutritional advisory and testing it in real world settings, e.g., a field test. Also, we will undertake further action research projects to learn from the method's 
application. A second step is an expert-based evaluation. This formative evaluation will be made in a series of guided interviews with experts [49] in the field of SE to validate the method. We will explore the method's understandability, its ability for engineering other KIPOS, strengths and weaknesses, as well as possible refinements.

\section{References}

[1] I. Alam and C. Perry, "A customer-oriented new service development process", Journal of Services Marketing, 16 (2002), pp. 515-534.

[2] M. Alavi, "An assessment of the prototyping approach to information systems development", Commun. ACM, 27 (1984), pp. 556-563.

[3] C. Alexander, Notes on the Synthesis of Form, Harvard University Press, Cambridge, MA, USA, 1973.

[4] U. M. Apte and R. O. Mason, "Global disaggregation of information-intensive services", Manage. Sci., 41 (1995), pp. 1250-1262.

[5] R. L. Baskerville and A. T. Wood-Harper, "A Critical Perspective on Action Research as a Method for Information Systems Research", Journal of Information Technology, 11 (1996), pp. 235-246.

[6] L. L. Berry and N. Bendapudi, "Health Care: A Fertile Field for Service Research", Journal of Service Research, 10 (2007), pp. 111-122.

[7] J. Bessant and L. Maher, "Developing Radical Service Innovations In Healthcare - The Role Of Design Methods", International Journal of Innovation Management, 13 (2009), pp. 555-568.

[8] M. J. Bitner, A. L. Ostrom and F. N. Morgan, "Service Blueprinting: A practical technique for service innovation", California Management Review, 50 (2008), pp. 66-94.

[9] Booz, Allen and Hamilton, New Products Management for the 1980s, Booz, Allen \& Hamilton, Inc., New York, 1982.

[10] C. Braun, F. Wortmann, M. Hafner and R. Winter, Method construction-a core approach to organizational engineering, ACM, 2005, pp. 1295-1299.

[11] S. Brinkkemper, "Method engineering: engineering of information systems development methods and tools", Information and Software Technology, 38 (1996), pp. 275280.

[12] M. Buchenau and J. F. Suri, Experience prototyping, ACM, 2000, pp. 424-433.

[13] H.-J. Bullinger, K.-P. Fähnrich and T. Meiren, "Service engineering - methodical development of new service products", International Journal of Production Economics, 85 (2003), pp. 275-287.

[14] H. Bullinger and P. Schreiner, "Service Engineering: Ein Rahmenkonzept für die systematische Entwicklung von Dienstleistungen", Service Engineering (2006), pp. 53-84.

[15] K.-H. Chai, J. Zhang and K.-C. Tan, "A TRIZ-Based Method for New Service Design", Journal of Service Research, 8 (2005), pp. 48-66.

[16] P.-T. Chuang, "Combining Service Blueprint and FMEA for Service Design", Service Industries Journal, 27 (2007), pp. 91-104.
[17] A. Crabtree, D. M. Nichols, J. O'Brien, M. Rouncefield and M. B. Twidale, "Ethnomethodologically informed ethnography and information system design", Journal of the American Society for Information Science, 51 (2000), pp. 666-682.

[18] H. Dubberly, S. Evenson and R. Robinson, "The Analysis-Synthesis Bridge Model", Interactions, 15 (2008), pp. 57-61.

[19] B. Edvardsson and J. Olsson, "Key concepts for new service development", The Service Industries Journal, 16 (1996), pp. 140-164.

[20] A. Essén, "The emergence of technology-based service systems: A case study of a telehealth project in Sweden", Journal of Service Management, 20 (2009), pp. 98-121.

[21] S. Fließ and M. Kleinaltenkamp, "Blueprinting the service company: Managing service processes efficiently", Journal of Business Research, 57 (2004), pp. 392-405.

[22] C. M. Froehle and A. V. Roth, "New measurement scales for evaluating perceptions of the technology-mediated customer service experience", Journal of Operations Management, 22 (2004), pp. 1-21.

[23] C. M. Froehle and A. V. Roth, "A Resource-Process Framework of New Service Development", Production \& Operations Management, 16 (2007), pp. 169-188.

[24] R. J. Glushko, Seven Contexts for Service System Design, in P. P. Maglio, C. A. Kieliszewsk and J. Spohrer, eds., Handbook of Service Science, Springer, New York, 2009.

[25] S. M. Goldstein, R. Johnston, J. Duffy and J. Rao, " The service concept: the missing link in service design research?", Journal of Operations Management, 20 (2002), pp. 121-134.

[26] J. Hauknes, Knowledge intensive services - what is their role?, OECD Forum on Realising the Potential of the Service Economy, Paris, 1999.

[27] B. Henderson-Sellers and J. Ralyté, "Situational method engineering: state-of-the-art review", Journal of Universal Computer Science, 16 (2010), pp. 424-478.

[28] G. Iachello, K. N. Truong, G. D. Abowd, G. R. Hayes and M. Stevens, Prototyping and sampling experience to evaluate ubiquitous computing privacy in the real world, Proceedings of the SIGCHI conference on Human Factors in computing systems, ACM, Montreal, Quebec, Canada, 2006, pp. 1009-1018.

[29] L. Jing-Hua, X. Lei and W. Xiu-Lan, "New service development using GAP-based QFD: a mobile telecommunication case.", International Journal of Services Technology \& Management, 12 (2009), pp. 146-174.

[30] J. Kartte, K. Neumann, F. Kainzinger and K.-D. Henke, Innovation und Wachstum im Gesundheitswesen, Roland Berger View, 2005.

[31] A. Karunakaran, S. Purao and B. Cameron, "From" Method Fragments" to" Knowledge Units": Towards a FineGranular Approach", ICIS 2009 Proceedings (2009), pp. 108. [32] D. Kindström and C. Kowalkowski, "Development of industrial service offerings: a process framework", Journal of service Management, 20 (2009), pp. 156-172.

[33] J. Kingman-Brundage and L. Shostack, "How to design a service", The AMA Handbook of Marketing for the Service Industries. Hrsg.: CA Congram, ML Friedman, New York (1991), pp. 243-261. 
[34] A. S. Lee, Action is an Artifact: What Action Research and Design Science Offer to Each Other, in N. Kock, ed., Information Systems Action Research, Springer, New York, 2007, pp. 43-60.

[35] P. Magnusson, "Benefits of involving users in service innovation", European Journal of Innovation Management, 6 (2003), pp. 228-238.

[36] D. Martin and I. Sommerville, "Patterns of cooperative interaction: Linking ethnomethodology and design", ACM Trans. Comput.-Hum. Interact., 11 (2004), pp. 59-89.

[37] J. Matthing, B. Sandén and B. Edvardsson, "New service development learning from and with customers", International Journal of Service Industry Management, 15 (2004), pp. 479-498.

[38] T. Meiren and T. Burger, ServLab: Visualising And Simulating New Services, RESER Conference papers, Stuttgart, 2008.

[39] P. Menschner, M. Hartmann and J. M. Leimeister, The nature of knowledge-intensive person-oriented services challenges for leveraging service engineering potentials, The Second International Symposium on Service Science ISSS 2010, Leipzig, Germany, 2010.

[40] P. Menschner, C. Peters and J. M. Leimeister, Engineering knowledge-intense, person-oriented services - A state of the art analysis, ECIS 2011 Proceedings, 2011.

[41] P. Menschner, A. Prinz, M. Altmann, P. Koene, F. Köbler, H. Krcmar and J. M. Leimeister, "Reaching into patients' homes - participatory designed AAL services - The case of patient-centered nutrition tracking service", Electronic Markets, 21 (2011), pp. 63-76.

[42] K. Meyer, M. Böttcher, M. Apitz and M. Opitz, Vorgehensmodelle im Kontext IT-basierter Dienstleistungen, Entwicklung IT-basierter Dienstleistungen, 2008, pp. 103126.

[43] J. Nielsen, Usability engineering, Morgan Kaufmann, 1993.

[44] J. Odell, A primer to method engineering, in S. Brinkkemper, K. Lyytinen and R. Welke, eds., Method Engineering, Chapman \& Hall, Ltd., London, 1996, pp. 1-7.

[45] OECD, OECD Health Data 2009, OECD Publishing, Paris, 2009.

[46] P. M. Oliveira and E. A. von Hippel, "Users as Service Innovators: The Case of Banking Services", MIT Sloan Research Paper No. 4748-09 (2009).

[47] M. Opitz, "When innovating services, are 12 Ps enough? Towards a design oriented framework.", International Journal of Services Technology \& Management, 9 (2008).

[48] L. Patrício, R. P. Fisk and J. F. Cunha, "Designing Multi-Interface Service Experiences: The Service Experience Blueprint", Journal of Service Research, 10 (2008), pp. 318334

[49] M. Q. Patton, Qualitative research and evaluation methods, Sage, Thousand Oaks, 2002.

[50] J. Pries-Heje and R. Baskerville, "The Design Theory Nexus", MIS Quarterly, 32 (2008), pp. 731-755.

[51] Z. Qi and K. Chuan Tan, Towards an integrative service design framework, Proceedings of the QUIS 11,, Wolfsburg, 2009.

[52] R. Ramaswamy, Design and management of service processes : keeping customers for life, Addison-Wesley, Reading, Mass. \{[u.a.], 1996.
[53] F. Resatsch, U. Sandner, J. M. Leimeister and H. Krcmar, "Do Point of Sale RFID-Based Information Services Make a Difference? Analyzing Consumer Perceptions for Designing Smart Product Information Services in Retail Business", Electronic Markets, 18 (2008), pp. 216-231.

[54] M. Schermann, A. Gehlert, K. Pohl and H. Krcmar, Justifying Design Decisions with Theory-based Design Principles, 17th European Conference on Information Systems (ECIS), Verona, Italy, 2009.

[55] E. Scheuing and E. Johnson, "A proposed model for new service development", Journal of Services marketing, 3 (1989), pp. 25-34.

[56] S. Schmidt-Rauch, R. Schaer and G. Schwabe, From Telesales to Tele-Advisory Services in Travel Agencies, ICIS 2010 Proceedings, 2010.

[57] M. K. Sein, O. Henfridsson, S. Purao, M. Rossi and R. Lindgren, "Action design research", Management Information Systems Quarterly, 35 (2011), pp. 37-56.

[58] J. Sheehan, "Understanding service sector innovation", Commun. ACM, 49 (2006), pp. 42-47.

[59] L. G. Shostack, " How to Design a Service", European Journal of Marketing, 16 (1982), pp. 49-63.

[60] L. Simons and J. F. Hampe, Service Experience Design for Healthy Living Support: Comparing an In-House with an eHealth Solution, BLED 2010 Proceedings, 2010.

[61] L. P. A. Simons and H. Bouwman, "Multi-channel service design process: challenges and solutions.", International Journal of Electronic Business, 3 (2005), pp. 50-67.

[62] A. M. Smith, M. Fischbacher and F. A. Wilson, "New Service Development: From Panoramas to Precision", European Management Journal (2007), pp. 370-383.

[63] J. Spohrer and S. K. Kwan, "Service Science, Management, Engineering, and Design (SSMED): An Emerging Discipline-Outline \& References", International Journal of Information Systems in the Service Sector (IJISSS), 1 (2009), pp. 1-31.

[64] E. Stevens and S. Dimitriadis, "Managing the new service development process: towards a systemic model", European Journal of Marketing, 39 (2005), pp. 175-198.

[65] J. C. Wei, Theories and principles of designing lean service process, Service Systems and Service Management, 2009. ICSSSM '09. 6th International Conference on, 2009, pp. 821-826.

[66] L.-C. Wu and L.-H. Wu, "Service Engineering: An Interdisciplinary Framework", Journal of Computer Information Systems, 51 (2010), pp. 14-23.

[67] H.-L. Yang and S.-L. Hsiao, "Mechanisms of developing innovative IT-enabled services: A case study of Taiwanese healthcare service.", Technovation, 29 (2009), pp. 327-337.

[68] R. K. Yin, Research Design Issues in Using the Case Study Method to Study Management Information Systems, in J. I. Cash and P. R. Lawrence, eds., The Information Systems Research Challenge: Qualitative Research Methods, Harvard Press, Boston, Mass., 1989, pp. 1-6.

[69] V. A. Zeithaml, M. Bitner and D. D. Gremler, Services marketing : integrating customer focus across the firm, McGraw-Hill/Irwin, Boston, 2006. 